\title{
Aplicações da desconvolução preditiva no processamento de dados sísmicos
}

\section{Patricia Santana de Sousa*, Romis Attux, Rafael Ferrari.}

\section{Resumo}

Para se obter uma imagem da subsuperfície através da sísmica de reflexão, é necessário filtrar uma série de distorções e ruídos que estão presentes nos dados sísmicos adquiridos em campo. A desconvolução preditiva é uma técnica de filtragem que pode ser usada para esse fim, destacando-se como ferramenta para desconvolução da assinatura da fonte e para atenuação de reflexões múltiplas.

\section{Palavras-chave:}

Desconvolução Preditiva, Filtros de Erro de Predição, Filtragem Ótima.

\section{Introdução}

No processo de imageamento, pulsos sísmicos são gerados na superfície. A energia do pulso sísmico se propaga em forma de onda através da subsuperfície, reflete nas interfaces entre camadas geológicas e é captada na superfície por sensores. Os sinais registrados, denominados sismogramas ou traços sísmicos, são usados para estimar a função de refletividade. Essa estimativa, combinada a um modelo de velocidade do subsolo, permite a obtenção de uma imagem em profundidade da subsuperfície.

A técnica de desconvolução preditiva pode ser utilizada para remover dois tipos de distorções comuns em dados sísmicos, um devido ao efeito da assinatura da fonte e o outro devido ao efeito das múltiplas reflexões entre diferentes camadas de uma estrutura geológica.

\section{Resultados e Discussão}

A função refletividade é uma série temporal, na qual cada impulso observado está associado à existência de uma interface entre camadas geológicas distintas. O traço sísmico pode ser modelado como a convolução da função refletividade com a assinatura da fonte mais um ruído de medida. Para se recuperar a função de refletividade a partir do traço sísmico, é necessário remover o efeito da assinatura da fonte. Um filtro de erro de predição progressivo (FEPP) linear foi utilizado para esse propósito.

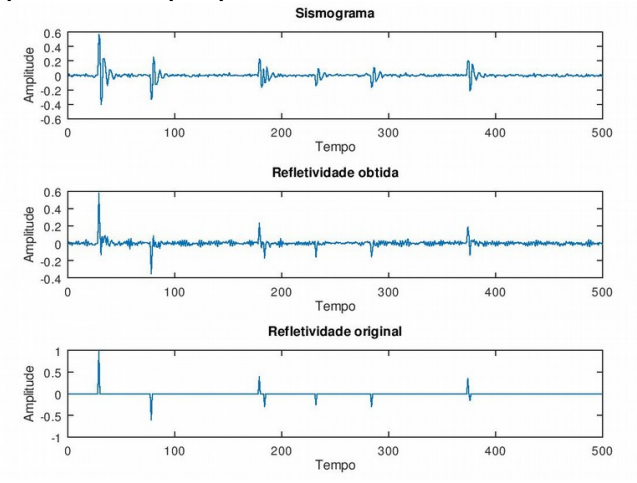

Figura 1. Exemplo de desconvolução do efeito de assinatura da fonte.

Um sísmograma sintético contendo a assinatura da fonte de fase mínima e ruído branco é mostrado na Figura 1. Esse traço foi filtrado com um FEPP de passo unitário para a obtenção da função de refletividade. Pode-se comparar a refletividade obtida com a refletividade original e observar que o efeito da assinatura da fonte foi atenuado após a filtragem.
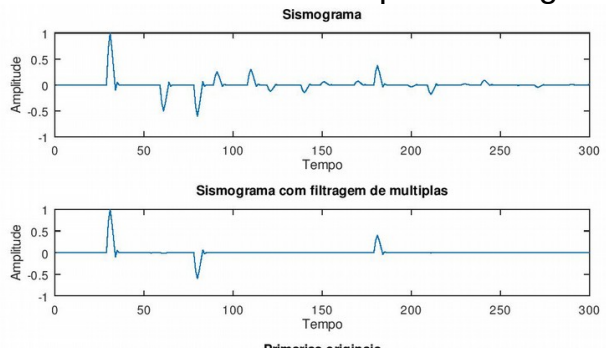

Primarias originais

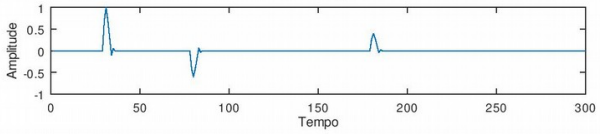

Figura 2. Exemplo de desconvolução do efeito de múltiplas reflexões.

Um traço sísmico contaminado por múltiplas reflexões pode ser modelado através da convolução das primárias com um sistema gerador de múltiplas, o qual é responsável por gerar repetições periódicas dos eventos primários. Um FEPP linear com passo de predição aproximadamente igual ao período das múltiplas, foi utilizado para prever e cancelar as repetições periódicas no traço sísmico da Figura 2. Pode-se comparar o sismograma filtrado com as primárias e observar que as múltiplas foram muito atenuadas após a filtragem.

\section{Conclusão}

Os resultados obtidos comprovam a eficácia do uso da técnica de desconvolução preditiva para remover distorções comuns em dados sísmicos. FEPP's a passo unitário podem ser usados para remover a assinatura da fonte, enquanto que FEPP's de passo arbitrário podem ser empregados para combater o efeito das múltiplas reflexões. Uma característica importante dessa técnica é o fato dela permitir que a desconvolução se dê de maneira não supervisionada, isto é, sem a necessidade de um sinal de referência. Essa característica é fundamental nos problemas abordados, uma vez que a refletividade e as primárias, que fariam o papel de referência, não estão disponíveis em casos práticos.

\section{Agradecimentos}

Projeto apoiado pelo CNPq. 